\title{
Formação continuada de professores: buscando melhorar e facilitar o ensino para deficientes visuais por meio de tecnologias assistivas
}

\author{
Miriam Ines Marchi* \\ Tânia Núsia da Costa Silva**
}

\section{Resumo}

Este artigo é um recorte da dissertação de Mestrado intitulada: "Deficiente visual: ensinando e aprendendo química através das tecnologias assistivas no ensino médio" e compreende a formação continuada de professores abordando tecnologias assistivas para deficientes visuais. $\mathrm{O}$ curso ofertado aos professores de químicas e auxiliares, que trabalham com alunos deficientes visuais, teve como principal objetivo promover o desenvolvimento de novas práticas pedagógicas a partir das tecnologias assistivas. Utilizou-se a técnica de observaçâo em duas escolas Estaduais de Boa Vista/RR para analisar as práticas e anseios dos professores e as necessidades dos alunos na sala de aula regular. A partir desta prática optou-se em promover o curso de Mecdaisy que é uma tecnologia brasileira que traz sintetizador de voz (narração e permite combinar texto, áudio e imagens para representar conteúdos). Constatou-se que a formação continuada possibilitou a reflexão e o crescimento tanto pessoal como profissional e a mudança nas práticas pedagógicas.

Palavras-chave: Tecnologias assistivas; Deficiente visual; Formação continuada.

* Professora doutora do Centro Universitário Univates, Lajeado, Rio Grande do Sul, Brasil.

** Mestre em Ensino de Ciências Exatas pelo Centro Universitário Univates, Lajeado, Rio Grande do Sul, Brasil. 


\section{Continued teacher education: seeking improvement for visually impaired teaching through assistive technologies}

\section{Abstract}

This article is an excerpt of the Master's thesis titled: "Visual Impairment: teaching and learning chemistry through assistive technologies in high school" and presents the continued education of teachers through the use of assistive technologies for the visually impaired. The course is offered to chemistry teachers and auxiliaries who work with visually impaired students, aimed to promote the development of new pedagogical practices by these assistive technologies. The observation method was used in two schools from the city of Boa Vista in Roraima to examine practices and concerns of the teachers and also the students' needs in the regular classroom. From this practice it was decided to promote a Mecdaisy course which is a Brazilian technology that deals with a voice synthesizer (narration and allows you to combine text, audio and images to represent content). It was observed that continuing education had enabled a reflection and growth both in personal and professional way and also a pedagogical practices' changing.

Keywords: Assistive technologies; Visually impaired; Continuing education.

\section{Introdução}

Atualmente fala-se muito sobre a cidadania da pessoa com necessidades educacionais especiais (NEE) e seus direitos e deveres para com a sociedade. Ou seja, discutem-se questóes a respeito do espaço que lhe compete como cidadáo integrado socialmente. É importante valorizar a diversidade, entendendo a diferença como algo enriquecedor, tanto para a vida educativa como social de todos. Neste cenário, destacam-se as pessoas com deficiência visual, as quais apresentam necessidades de manusear recursos específicos e adequados para alcançar seu desenvolvimento integral e realizar atividades voltadas para o que é inerente a sua deficiência, de modo a potencializá-las, tais como o aprendizado de química do ensino médio por meio do uso das Tecnologias Assistivas - TA.

Partindo deste contexto, a possibilidade do aluno aprender as ciências exatas, mais precisamente a Química, amplia-se, pois, as tecnologias assistivas podem propiciar, a estes alunos, maior estímulo visual facilitando a comunicação, a aprendizagem e mais independência na realização das atividades desta disciplina em sala de aula regular.

Segundo CAT (2007) a partir das tecnologias assistivas, as possibilidades dos alunos com deficiência visual de superar suas dificuldades funcionais no ambiente da sala de aula e fora dela podem ser maiores, uma vez que estas tecnologias são recursos que potencializam as habilidades funcionais das pessoas com deficiência. 
Quando se trata de pessoas com deficiência, o conceito de deficiente deve ser pensado de forma a atender o que elas realmente são: "pessoas como você: têm os mesmos direitos, sentimentos, sonhos e vontades. Ter uma deficiência não torna a pessoa melhor ou pior. O portador de deficiência não é um anjo, nem um modelo de virtudes: é uma pessoa! ” (GIL, 2000 p. 19).

Assim, com o intuito de proporcionar condiçóes equivalentes a todas as pessoas com deficiências, foi criado o Comitê de Ajudas Técnicas pelo Decreto n ${ }^{\circ}$ 5.296/2004, vinculado à Secretaria Nacional de Promoção das Pessoas com Deficiência (SNPD). Este Comitê propóe a criação de políticas públicas, aos órgãos competentes, relacionadas com o desenvolvimento e uso de Tecnologias Assistivas - TA (BRASIL, 2004).

Assim, o Comitê de Ajudas Técnicas - CAT, por compreender que a evolução tecnológica "ajuda a vida a ser mais fácil e a tornar os fatos possíveis", conceitua a tecnologia assistiva como sendo:

Uma área do conhecimento, de característica interdisciplinar, que
engloba produtos, recursos, metodologias, estratégias, práticas e
serviços que objetivam promover a funcionalidade, relacionada à
atividade e participaçáo, de pessoas com deficiência, incapacida-
des ou mobilidade reduzida, visando sua autonomia, independên-
cia, qualidade de vida e inclusáo social. (CAT, 2007, p. 4).

Também, Tecnologias Assistivas “[...] é todo e qualquer item, equipamento ou parte dele, produto ou sistema fabricado em série ou sob medida, utilizado para aumentar, manter ou melhorar as capacidades funcionais das pessoas com deficiência" (BRASIL, 2009, p. 43).

Dentro dos recursos de acessibilidade ao computador, pode-se citar o sistema Mecdaisy que é, segundo a Equipe Mecdaisy do CAP-DV/RR - Centro de Apoio Pedagógico para Atendimento à Pessoa com Deficiência Visual de Boa Vista Roraima, diferente de outros softwares leitores de texto no computador por apresentar facilidade de navegação pelo texto sonoro de maneira semelhante ao texto escrito, permite que o usuário folheie, consulte o índice, pesquise e faça comentários. Segundo a Nota Técnica no 58/2013/MEC/SECADI/DPEE o Mecdaisy possibilita "a geração de livros digitais falados e sua reprodução em áudio, gravado ou sintetizado. [...] permitindo a reprodução sincronizada de trechos selecionados, o recuo e o avanço de parágrafos e a busca de seçóes ou capítulos" (BRASIL, 2013, p. 1).

Portanto, trata-se de uma tecnologia que permite combinar texto, áudio e imagens para representar conteúdos como livros, artigos, etc., a ferramenta brasileira traz sintetizador de voz (narração) e instruções de uso em português brasileiro.

Dentre os quatro princípios propostos para a educação do século XXI de Delors (2004), 'Aprender a Conhecer', 'Aprender a Fazer', 'Aprender a Viver Juntos' e 'Aprender a Ser', destaca-se, principalmente o aprender a conhecer, base que qualifica o fazer, o conviver e o ser - síntese de uma educação que prepara o indivíduo e a sociedade para os desafios futuros, como o de aceitar e saber manusear as tecnologias 
assistivas e preparar-se para as constantes e aceleradas transformaçóes e diferenças existente no mundo.

Neste processo de sistematização do conhecimento, o professor tem função fundamental, pois este se torna o intermediador, desafiador e encorajador do estudante através de estratégias pedagógicas que busquem analisar determinadas situaçôes e melhorá-las, adaptando os pressupostos teóricos à sua própria realidade reorientando-se em funçáo dos dados que tal realidade lhe oferece. "Essa concepçáo de Educação como formação humana que se dá em uma pluralidade de espaços sociais amplia a visão dos processos educativos e consequentemente alarga o leque dos educadores" (RODRIGUES, 2006, p. 176).

Logo, a formação do professor é, sem dúvida, uma questão imprescindível para a concretização da inclusão educacional. Os docentes precisam aprender sobre as deficiências, distúrbios, transtornos e dificuldades para saber diferenciá-los. Assim, a formação de professores na modalidade de educação especial é assumida como um fator decisivo para a inclusão de alunos que necessitam de AEE, porém vale destacar que nos dias atuais, a capacitaçáo necessita incidir sobre as tecnologias assistivas que auxiliam estes alunos a ter uma vida mais igualitária. Por meio da contínua formação o professor poderá construir uma base de conhecimentos sobre a área da TA em especial a recursos educacionais para a acessibilidade e aprendizagem, como materiais didáticos em Braille, áudio, computadores com programas de sintetizador de voz, softwares para comunicação, bem como outras ajudas técnicas que possibilitam o acesso ao conhecimento.

O professor que domina a TA pode favorecer oportunidades excepcionais, pois estas tecnologias auxiliam o aluno com deficiência "[...] maior independência, qualidade de vida e inclusão social, através da ampliação de sua comunicação, mobilidade, controle de seu ambiente, habilidades de seu aprendizado e trabalho" (BERSCH, 2013, p. 2).

Partindo da concepção que as Tecnologias Assistivas contribuem para a inclusão de alunos com NEE no sistema educacional, este artigo se constituiu de um recorte da dissertação de Mestrado intitulada "Deficiente visual: ensinando e aprendendo química através das tecnologias assistivas no ensino médio", do Programa de Pós-Graduação em Ensino de Ciências Exatas do Centro Universitário - UNIVATES. A proposta integral da pesquisa foi analisar se e como as Tecnologias Assistivas, utilizadas no Centro de Apoio Pedagógico para Atendimento à Pessoa com Deficiência Visual de Boa Vista Roraima - CAP/DV/RR contribuem para aprendizagem dos conteúdos de Química no Ensino Médio, bem como buscar facilitar, por meio de uma formaçáo continuada utilizando tecnologias assistivas, a prática pedagógica dos profissionais das Escolas do qual os alunos deficientes visuais são oriundos.

Neste recorte a finalidade é discutir a importância do curso de formação continuada com tecnologias assistivas ministrado a partir da pesquisa, no qual buscou desenvolver novas habilidades nos professores para trabalharem com alunos deficientes visuais. Desta forma, optou-se em promover o curso de Mecdaisy. 


\section{Metodologia da pesquisa}

Constitui-se como metodologia para o presente artigo o paradigma interpretativo de enfoque qualitativo, a partir da técnica de observação, além do instrumento de coleta de dados - questionário e outras anotações.

A pesquisa qualitativa, segundo Appolinário (2012, p. 61), "prevê a coleta dos dados a partir de interaçóes sociais do pesquisador com o fenômeno pesquisado". Nesse sentido, buscou-se identificar os possíveis entendimentos delineados pelos pesquisados sobre o conceito de formação continuada de professores em tecnologias assistivas no auxílio aos deficientes visuais.

A pesquisa qualitativa nesta investigação se prendeu a aspectos reais que não podem ser quantificados, centrando-se na compreensão e explicação das relações dos participantes com o meio. Assim, a partir dos materiais coletados por meio do questionário, foi possível analisar os resultados com base em fundamentos teóricos visando entender e interpretar o universo de significados das relaçóes e dos processos dos participantes da pesquisa e ofertar o curso de formação continuada.

Seguindo a caracterização teórica da pesquisa, a técnica utilizada foi a observação, na qual, segundo Oliveira $(2010$, p. 23) "é o instrumento que mais fornece detalhes ao pesquisador" devido "Possibilitar-nos ver o comportamento dos participantes em uma nova luz e descobrir novos aspectos do contexto". Para a técnica de observação há vários instrumentos que podem ser utilizados para coletar os dados, nesta pesquisa empregou-se: anotaçôes, no qual foi realizada a análise das informaçôes e dos comentários durante a execução do trabalho.

O curso de formação continuada em Tecnologia Assistiva Mecdaisy teve carga horária de 20 horas, sendo realizado durante uma semana (05 encontros) em 2013 no CAP/DV-RR. As atividades desenvolvidas (Quadro 1) consistiram de apresentação e discussão de literaturas a respeito do tocador Mecdaisy e atividades práticas nos computadores com o programa já instalado e posteriormente debates sobre as experiências pessoais de cada um dos participantes. 
Quadro 1 - Relação das atividades e dos textos estudados nos encontros de formação continuada.

\begin{tabular}{|c|c|c|}
\hline ENCONTROS & ATIVIDADE & TEXTO ESTUDADO \\
\hline \multirow{3}{*}{$1^{\circ}$ encontro } & \multirow{2}{*}{\begin{tabular}{|l|} 
Apresentação do curso; \\
$\begin{array}{l}\text { Entrega do material em } \\
\text { pendrive; }\end{array}$ \\
\end{tabular}} & \\
\hline & & \\
\hline & $\begin{array}{l}\text { Instalação do software } \\
\text { Mecdaisy. }\end{array}$ & \\
\hline \multirow[b]{2}{*}{$2^{\circ}$ encontro } & $\begin{array}{l}\text { Orientação para converter } \\
\text { qualquer texto no formato } \\
\text { Daisy; }\end{array}$ & \multirow[b]{2}{*}{$\begin{array}{l}\text { Nota técnica N. 21/2012/ } \\
\text { MEC/SECADI/DPEE }\end{array}$} \\
\hline & $\begin{array}{l}\text { Orientaçãoes para descrição } \\
\text { de imagem na geração de } \\
\text { material digital acessível - } \\
\text { Mescdaisy. }\end{array}$ & \\
\hline \multirow{3}{*}{$3^{\circ}$ encontro } & $\begin{array}{l}\text { Criação do material do } \\
\text { cursista; }\end{array}$ & \multirow{3}{*}{$\begin{array}{l}\text { Lenda do Curupira; Texto } \\
\text { do livro didático do } 6 \text { ano; } \\
\text { Reação química. }\end{array}$} \\
\hline & $\begin{array}{l}\text { Conversão de textos em } \\
\text { Daisy; }\end{array}$ & \\
\hline & $\begin{array}{l}\text { Descrição de figuras com } \\
\text { legendas. }\end{array}$ & \\
\hline \multirow{3}{*}{$4^{\circ}$ encontro } & $\begin{array}{l}\text { Conversão de textos em } \\
\text { Daisy; }\end{array}$ & \multirow{3}{*}{$\begin{array}{l}\text { Textos variados; } \\
\text { Produção individual }\end{array}$} \\
\hline & $\begin{array}{l}\text { Descrição de figuras com } \\
\text { legendas. }\end{array}$ & \\
\hline & $\begin{array}{l}\text { Aprendendo sem olhar: } \\
\text { executar a produção do } \\
\text { colega só ouvindo o tocador } \\
\text { Mecdaisy. }\end{array}$ & \\
\hline \multirow[t]{2}{*}{$5^{\circ}$ encontro } & $\begin{array}{l}\begin{array}{l}\text { Dinâmica avaliativa dos } \\
\text { conteúdos; }\end{array} \\
\end{array}$ & \multirow[t]{2}{*}{ Dinâmica do desafio } \\
\hline & Avaliação do curso & \\
\hline
\end{tabular}

Os sujeitos escolhidos para esta pesquisas foram os dois (02) professores de Química e dois (02) professores auxiliares que trabalham nas Escolas Estaduais em que estudam os dois (02) alunos com deficiência visual e frequentam o CAP. Para ministrar o curso em Tecnologias Assistivas, além da mestranda, foram convidadas duas professoras do Centro de Apoio Pedagógico para Atendimento à Pessoa com Deficiência Visual de Boa Vista/RR - CAP/DV/RR, pois para o curso ter legalidade deve ser ministrado por estas profissionais que tem legitimidade para emitir certificado reconhecido pelo MEC. 
Após a formação continuada utilizou-se também o questionário como um dos instrumentos de coleta de dados com a intenção de colher dos participantes percepçôes e contribuiçóes a respeito do curso em tecnologias assistivas para seu trabalho em sala de aula.

\section{Resultados e discussões}

Os quatro participantes do curso de formação continuada foram caracterizados da seguinte forma: PI e PII, professores da Escola 1 que trabalham com o aluno 1 e PIII e PIV da Escola 2, onde estuda Aluno 2. Inicialmente foi apresentada a estes professores a proposta da pesquisa de Mestrado enfatizando-se que um dos objetivos era promover uma formação continuada na área de Tecnologias Assistivas aos professores dos alunos em questão.

Os professores foram muito atenciosos e receptivos, se comprometendo em participar do curso, pois necessitavam aprender sobre as tecnologias assistivas que alunos deficientes visuais utilizavam no $\mathrm{CAP}$, mas que eles não tinham domínio e não utilizavam em sala de aula. Também, estes autorizaram, por meio do Termo de Consentimento Livre e Esclarecido (TLCE), a mestranda a realizar observaçóes de suas aulas nas escolas para posteriormente promover a formação continuada. $\mathrm{O}$ procedimento de observação foi utilizado nas Escolas Estaduais como método para gerar subsídios pertinentes à promoção do curso de formação continuada. A partir desta prática foi possível extrair o significado que os participantes atribuem a sua realidade e suas próprias ações.

Primeiramente acompanhou-se, na Escola 1, o professor titular e o auxiliar do aluno 1 (PI e PII respectivamente) que consentiram a observaçáo das aulas de química durante 2 semanas no período noturno. O PI, formado em Licenciatura em Química e especialista em Tecnologias na Educação, não conhecia o sistema Braille e era a primeira vez que trabalhava com aluno deficiente visual. Por este motivo, mesmo conhecendo, por meio de literaturas, algumas tecnologias assistivas, não dominava nenhuma. Ele é um professor muito preocupado com esta situaçáo e se comunica constantemente com o professor auxiliar (PII), que é pedagogo e especialista em educação especial, com alguns cursos na área. O PII, apesar de sua formação e conhecimento na área da deficiência visual, não entendia muito da disciplina de química e relatou que era a primeira vez que trabalhava com aluno no ensino médio. Assim, precisava aprender mais sobre as tecnologias que auxiliam no ensino e na aprendizagem das ciências exatas.

Quanto à dinâmica das aulas no período da observação, PI repassava os conteúdos antecipados para PII que estudava em casa e depois explicava mais detalhadamente para o aluno 1. Como era início das aulas da modalidade EJA, o professor titular trabalhou explicando a química no cotidiano. De forma informal, o aluno 1 relatou que aqueles conteúdos vistos até aquele momento, ele havia conseguido aprender na sala de aula, com a ajuda do professor auxiliar.

Na Escola 2, os professores PIII e PIV (titular e auxiliar) consentiram, também a observação durante as aulas de química no período vespertino, igualmente por 
2 semanas. O PIII, também formada em Licenciatura em Química com especialização em Metodologia do Ensino Superior, disse que não conhecer nada sobre Braille e muito menos sobre tecnologias assistivas para alunos cegos. Declarou que o aluno 2 era muito inteligente e dominava os recursos como ninguém. O professor auxiliar PIV é biólogo, com bastante experiência na docência e recentemente optou em trabalhar com alunos especiais. Não tem especialização, mas fez o curso de capacitação em Braille. Não conhece as tecnologias assistivas que o aluno 2 usa no CAP. Aceitou participar do curso se o horário fosse compatível com o dele.

\section{Formação continuada de professores}

Após analisar as práticas e anseios dos professores e as necessidades dos alunos na sala de aula regular, promoveu-se o curso de Mecdaisy, que é um programa baseado nos padróes internacionais Daisy - Digital Accessible Information System (Sistema de Informação Digital Acessível). Ou seja, Mecdaisy é uma tecnologia que permite combinar textos, áudios e imagens para representar conteúdos como livros, artigos, etc., a ferramenta brasileira traz sintetizador de voz (narração) e instruções de uso em português brasileiro.

As atividades do curso de formaçáo continuada ocorreram com um grupo composto pelos quatro professores das Escolas Estaduais, pela mestranda e por duas professoras (ministrantes) do CAP. No primeiro dia a formação continuada iniciou com uma conversa informal, na qual cada participante se apresentava e falava de suas expectativas em relaçáo ao curso. Após este primeiro contato, notou-se que os participantes tinham interesse em aprender a utilizar as tecnologias assistivas, não só para suprir uma necessidade momentânea, mas também para adquirir conhecimento sobre as ferramentas que auxiliam a inclusão de pessoas com algum tipo de deficiência.

A partir das apresentaçóes, os participantes começaram a prática navegando no livro sugerido pelas professoras ministrantes, que eles, a princípio, ficaram receosas com a forma de manusear esta ferramenta. Ao perceber esta inquietude, as professoras ministrantes explicaram que este impacto era normal e, apesar de não ser simples era muito mais fácil para os não videntes porque eles têm os outros sentidos mais aguçados. Esta aula de navegaçáo nos livros incidiu para o reconhecimento das funçôes da ferramenta que seriam exploradas posteriormente.

No segundo dia à apresentação do programa Mecdaisy iniciou com a teoria e simultaneamente a parte prática. Cada participante ficou responsável por desenvolver suas atividades em um dos computadores do laboratório de informática do CAP, ou seja, criar materiais em Daisy não disponíveis ainda pelo MEC. A atividade realizada neste dia consistiu na criação de descriçôes de imagens na geração de material digital acessível-Mecdaisy.

Com auxílio das professoras ministrantes, e das orientaçôes para descrição de imagem na geração de material digital acessível-Mecdaisy (BRASIL, 2012), as imagens eram criadas (descritas) no tocador Mecdaisy, já instalados nos computadores. Este processo consistiu da traduçáo das imagens em palavras, como por exemplo, retrato de pessoas, paisagens, objetos, cenas e ambientes, no entanto, sempre consi- 
derando o que as ministrantes orientaram: "nunca expressar julgamento ou opinióes pessoais a respeito".

Depois de criadas as descrições das imagens, solicitou-se que os participantes trocassem de lugar, fechassem os olhos e ouvissem as criaçóes dos colegas e na sequência, descrevessem o que entenderam. Todos se divertiram muito ao constatar que as figuras criadas ficaram sem sentido, falando: "Nossa eu não entendi nada do que está dizendo aqui. Sei que é uma descrição de tira cômica, mas não compreendi o que ela está fazendo" (PII). Houve mais algumas discussōes a respeito da forma mais adequada, segundo os requisitos acessíveis-Mecdaisy de se criar imagens, e por isso, esta atividade se estendeu por mais um dia, pois a construção das descriçôes das imagens deve seguir alguns requisitos padronizados pelas Normas Técnica No 21/2012.

No dia seguinte, ou seja, no quarto encontro, o curso continuou com a criação de figuras juntamente com textos. Foram criados livros de histórias, como por exemplo, o Curupira, Macunaima, Yanomamis e também parte de livros didáticos. Apesar de ser uma tarefa demorada que requer paciência, dedicação e muita atenção, os participantes se mostraram interessados em aprender como produzir materiais que facilitam a aprendizagem do aluno com deficiência visual.

Após esta atividade, verificou-se que os professores, mesmo encontrando algumas dificuldades na produção de material, acreditam que as Tecnologias Assistivas são recursos facilitadores de aprendizagens e por isso vale dedicar um pouco de tempo ao aperfeiçoamento destas ferramentas que auxiliam o aluno a ter uma vida mais igualitária.

Segundo Nóvoa (2001, p. 14), em entrevista dada a Revista Escola "O aprender contínuo é essencial e se concentra em dois pilares: a própria pessoa, como agente, e a escola, como lugar de crescimento profissional permanente". Ao se referir à formação do professor, este autor declara que o processo de formação continuada, apesar de ser decisáo individual, é um trabalho coletivo que depende da experiência e da reflexão de cada um continuamente.

Desta forma, este curso de formação continuada com as tecnologias assistivas buscou desenvolver novas habilidades nos professores para trabalharem com alunos deficientes visuais e um dos aspectos destacado foi o compromisso social, que para Nóvoa (2010), valoriza os princípios da inclusáo social e a diversidade cultural.

Esta formação foi planejada com a perspectiva de que o professor necessita de formação constante para aprender sempre e em ofício. Assim, buscou-se vincular teoria à prática nas atividades desenvolvidas no laboratório de informática, o qual instigou os participantes à reflexão sobre sua docência, de modo a ampliar seus conhecimentos e adquirir domínio sobre novas informaçóes, conforme declarou PIV: "A teoria aliada à prática é muito importante, pois nos faz refletir sobre o que devemos aprender ou aprimorar. No meu caso sei que tenho muito a aprender, no entanto sei que não é coisa de outro mundo estas tecnologias". Analisando tal depoimento, percebe-se que a formação continuada tem para cada professor a possibilidade de transformar suas práticas pedagógicas. No entanto, vale ressaltar que esta prática profissional deve 
estar embasada em teoria e em sua reflexão, a qual conduzirá para mudança e transformação no contexto escolar. Conforme Imbernón (2010, p. 75) “o conhecimento profissional consolidado mediante a formação permanente apoia-se na aquisição de conhecimentos teóricos e de competências de processamento da informação, análise e reflexão crítica em, sobre e durante a ação".

Outro aspecto destacado no curso foi o trabalho colaborativo dos participantes que foi essencial para o bom andamento do curso. Para Nóvoa, (2002, p. 39) "a troca de experiência e a partilha de saberes consolidam espaços de formação mútua, nos quais cada professor é chamado a desempenhar, simultaneamente, o papel de formador e de formando".

No último encontro de formação continuada utilizou-se uma dinâmica em que o participante trabalhava individualmente. Apesar do receio de errar, pois a atividade era realizada em um computador que projetava a imagem em uma tela grande para que todos vissem, as tarefas foram sendo efetivadas sem problemas e com precisão que exigia as normas para produção de materiais em Daisy. A aprendizagem foi acontecendo gradativamente com a teoria e a prática. Percebeu-se que a formação docente que provoca mudanças reais na prática de ensino é fator essencial na qualidade da educação e da inclusão. A formação continuada voltou-se para o professor que já atuava com alunos deficientes visuais e, desta forma, contribuiu para ele ampliar, modificar ou somente aprimorar de forma crítica a própria prática. Uma mudança que acontece por meio da reflexão sistemática do fazer pedagógico.

Aplicou-se um questionário com o intuito de colher dos participantes as percepçóes e contribuiçóes a respeito do curso em tecnologias assistivas para seu trabalho em sala de aula, A primeira questão solicitava a opiniáo deles sobre a metodologia empregada no curso em tecnologias assistivas. Dentre as respostas, PIII e PIV relatam que:

Aprender a teoria e a prática juntas é muito mais significativo, assim o curso está de parabéns, por proporcionar tal dinâmica (PIII).

Muito boa. Consegui aprender na prática o que estava sendo ensinado na teoria, sem contar que as dúvidas e dificuldades foram elucidadas aqui mesmo (PIV).

Observa-se, a partir dos depoimentos, que os participantes acreditam que a articulação entre a teoria e a prática, concomitantemente nos cursos de formação continuada possibilita uma ação mais imediata e concreta com os alunos no processo de ensino e aprendizagem, uma vez que suas próprias dificuldades podem ser esclarecidas durante o curso e náo depois.

Quando se vincula a teoria e a prática em um processo de formação continuada pode-se, com isso, estabelecer um repensar de açóes sobre os aspectos que permeiam a construçáo do trabalho docente tanto na escola como os alunos como nas políticas educacionais. A reflexão sobre o exercício educacional a partir do campo teórico juntamente com a prática, estimula a análise da realidade do ensino e da troca de experiências tornando possível a compreensão, a interpretação e a intervenção sobre a prática (IMBERNÓN, 2010). 
$\mathrm{Na}$ questão que versava sobre as contribuiçôes que o curso teve para a prática educacional dos participantes enquanto professores de alunos com NEE, PII destaca que: "Para mim, foi excelente o curso. Vemos que saber utilizar as tecnologias assistivas é favorecer igualdade aos alunos com NEE".

Constata-se, portanto, que os professores começaram a perceber as Tecnologias Assistivas como recursos que facilitam as aprendizagens dos alunos com NEE. Sobre esta concepção, Bersch $(2013$, p. 2) afirma que a TA "deve ser entendida como um auxílio que promoverá a ampliação de uma habilidade funcional deficitária ou possibilitará a realização da função desejada e que se encontra impedida por circunstância de deficiência ou pelo envelhecimento". Estas considerações apontam para o alcance dos objetivos do curso de formação continuada dentro da proposta de intervenção da pesquisa, ou seja: refletir sobre a própria prática docente e perceber que existem alternativas bem-sucedidas que levam, de fato, à inclusão social de alunos com NEE.

Quando questionados sobre as percepções deles em relação à formação continuada para profissionais da educação, os participantes deixaram claro que a formação continuada necessita auxiliar o professor, tanto a superar suas dificuldades quanto auxiliar a enfrentá-las e, principalmente a solucionar problemas de se trabalhar com alunos deficientes por meio das tecnologias assistivas. Ainda, foi possível perceber que os professores buscam os cursos de formação continuada, basicamente, a partir da própria necessidade de se aperfeiçoar e de melhorar o seu desempenho em sala de aula quanto às dificuldades que sentem em dominar determinadas áreas de conhecimento e, também pela necessidade da progressão na carreira, de acordo com o plano de cargos e salários do Estado.

A quarta questão verificou como os participantes avaliavam as atividades desenvolvidas a partir do curso Mecdaisy, além do conhecimento adquirido manuseando o sistema. Neste quesito, também os instigou a uma autorreflexão e pelas respostas, os participantes demonstram que eles aproveitaram a oportunidade de participar e destacaram que tiveram muitos "ganhos" com as informaçóes sobre as tecnologias assistivas, uma vez que aprenderam, sem grandes dificuldades, a manusear o sistema Mecdaisy em curso e nas escolas. É possível perceber que os professores entenderam este curso como o começo de uma nova etapa na formaçáo que deve ser mesmo continuada. Como afirma Freire, (1991, p. 58) "ninguém nasce educador ou marcado para ser educador. A gente se faz educador, a gente se forma, como educador, permanentemente, na prática e na reflexão da prática”.

Para a última questão, foi solicitado aos participantes que atribuíssem uma nota de zero a 10 para o curso de modo geral. A média geral do curso obtida a partir das notas de cada participante foi de 9,5, o que indica que os principais objetivos da proposta de formaçáo continuada em tecnologias assistivas foram alcançados. Melhor dizendo, os conteúdos estudados e a metodologia empregada constituíram importantes subsídios para a reflexão da prática do professor quanto à inclusão de alunos com NEE em sala regulares do ensino médio. 


\section{Conclusão}

Considerando os resultados obtidos nesta pesquisa constata-se, que mesmo que a inclusão se efetive com uma educação para todos e com um ensino voltado para as especificidades do aluno, não se consegue a inserção desta proposta sem pensar na formação dos professores. Desta forma, este curso ofertado aos professores das escolas estaduais em que estudam dois alunos deficientes visuais proporcionou a reflexão sobre a própria prática docente e a compreensão que há alternativas mais dinâmicas e precisas que levam a inclusão dos alunos com NEE.

Os participantes perceberam que o ofício de ser professor deve ser visto como uma profissão e, assim como qualquer outra, requer formação inicial, continuada e um repensar sobre a própria prática. Logo, a partir dos resultados reflete-se sobre quão importante são os saberes da docência e, mais do que isso, como é necessário o professor permitir-se a novos conhecimentos que possibilite a troca de experiências, o olhar sobre as necessidades do outro, podendo assim, favorecer uma prática pedagógica diferenciada e adequada a cada particularidade.

Desta forma, torna-se indispensável que os cursos de formação continuada possibilitem a interação entre as dimensôes pessoais e profissionais, de modo que a prática pedagógica seja reflexiva no sentido de fazer modificaçôes pertinentes em busca de melhorar o desenvolvimento pessoal, profissional e do educando. Para concluir, concorda-se com as palavras de Sá, Campos e Silva (2013, p. 13): ao se "conhecer, reconhecer e aceitar as diferenças como desafios positivos, pode-se descobrir e reinventar estratégias e atividades pedagógicas condizentes com as necessidades gerais e específicas de todos e de cada um".

\section{Referências}

APPOLINÁRIO, F. Metodologia da ciência. 2 ed. São Paulo. Cengage Learning, 2012.

BERSCH, R. Introduçáo à Tecnologia assistiva. Porto Alegre, 2013. Disponível em: <http://www.assistiva. com.br/Introducao\%20TA\%20Rita\%20Bersch.pdf>. Acesso em: 09 fev. 2014.

BRASIL. Decreto n. $\mathbf{5 . 2 9 6}$ de 02 de dezembro de 2004 - DOU de 03/122004. Disponível em: <http://www. planalto.gov.br/ccivil/_ato2004-2006/2004/decreto/d5296.htm>. Acesso em: 14 set. 2012.

Subsecretaria Nacional de Promoção dos Direitos da Pessoa com Deficiência. Comitê de Ajudas Técnicas. Tecnologia Assistiva. Brasília: CORDE, 2009.

Ministério da Educação. Secretaria de Educação Continuada, Alfabetização, Diversidade e Inclusão. Nota Técnica n. 21/2012/MEC/SECADI/DPEE. SECADI. Brasília, 2012.

Ministério da Educação. Secretaria de Educaçấo Continuada, Alfabetização, Diversidade e Inclusão. Nota Técnica n. 58/2013/MEC/SECADI/DPEE. SECADI. Brasília, 2013.

CAT, 2007. Ata da Reunião VII, de dezembro de 2007, Comitê de Ajudas Técnicas. Secretaria Especial dos Direitos Humanos da Presidência da República (CORDE/SEDH/PR). Disponível em: <http://www.mj.gov.br/ corde/arquivos/doc/Ata_VII_Reunião_do_Comite_de_Ajudas_Técnicas.doc>. Acesso em: 12 set. 2012.

DELORS, J. Educação, um tesouro a descobrir. São Paulo: Brasília, DF: MEC: UNESCO, 2004.

FREIRE, M. A formação Permanente. In: FREIRE, P. Trabalho, comentário, reflexão. Petrópolis: Vozes, 1991.

GIL, M. Deficiência Visual. Brasília: MEC, Secretaria de Educaçấo a Distância, 2000.

IMBERNÓN, F. Formaçáo continuada de professores. Porto Alegre: Artmed, 2010.

LIBÂNEO, J. C. Adeus professor, adeus professora? São Paulo: Cortez, 1998. 
NÓVOA, A. Formaçáo de professores e trabalho pedagógico. Lisboa: Educa, 2002.

. Profissăo docente. Revista Nova Escola. São Paulo, n. 142, maio. 2001.

OLIVEIRA, A. A. de. Observação e entrevista em pesquisa qualitativa. Revista Científica da Faculdade Cenecista de Vila Velha/FACEVV. v. 2, n. 4, (jan./jun. 2010). Vila Velha: FACEVV, 2010.

RODRIGUES, A. J. Contextos de aprendizagem e integração/inclusão de alunos com necessidades educativas especiais. In: RIBEIRO, M. L. S.; BAUMEL, R. C. R. (Org.). Educação Especial: do querer ao fazer. São Paulo: Avercamp, 2006.

SÁ, E. D. de; CAMPOS, I. M. de; SILVA, M. B. C. Atendimento educacional especializado: deficiência visual. Brasília: SEESP/SEED/MEC, 2007.

\section{Correspondência}

Miriam Ines Marchi - Centro Universitário Univates, CETEC. Rua Avelino Tallini, 171 - Prédio 5 - Sala 200, Universitário, CEP: 95900-000, Caixa-postal: 171 - Lajeado, Rio Grande do Sul - Brasil.

E-mail: mimarchi@univates.br - tanianusia@hotmail.com

Recebido em 15 de dezembro de 2015

Aprovado em 20 de janeiro de 2016 
